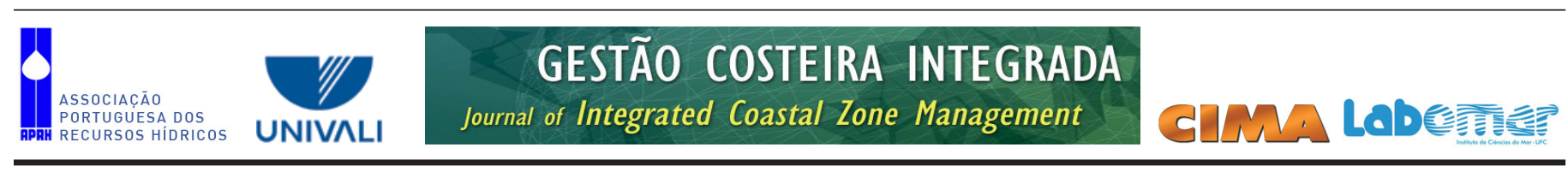

http://www.aprh.pt/rgci/pdf/rgci-428_Santos.pdf | DOI:10.5894/rgci428

\title{
A Pesca Artesanal na Comunidade de Fernão Velho, Maceió (Alagoas, Brasil): de Tradicional a Marginal *
}

\author{
The Artisanal Fisheries in the Community of Fernão Velho, Maceió (Alagoas, Brazil): \\ From Traditional To Marginal
}

\author{
Everson Cardoso dos Santos ${ }^{\circledR, 1}$, Cláudio Luis Santos Sampaio ${ }^{2}$
}

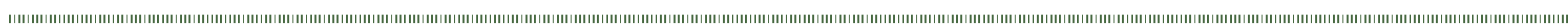

\section{RESUMO}

A lagoa Mundaú faz parte de um complexo estuarino de grande importância econômica para a população que vive em seu entorno. Porém, ao longo do tempo, esse ecossistema vem sendo afetado por uma variedade de impactos antrópicos, o que tem comprometido a atividade pesqueira na região. Registramos, neste trabalho, o processo de declínio da pesca artesanal em Fernão Velho, comunidade localizada na malha urbana da cidade de Maceió, estado do Alagoas, Nordeste do Brasil. Para a coleta de informaçóes, foram utilizadas entrevistas livres e semiestruturadas, e, para a seleção dos entrevistados, foi utilizada a técnica Snowball Sampling. Os resultados mostram que a pesca artesanal já não garante o sustento dos pescadores tradicionais e de suas famílias, o que tem contribuído para o declínio do conhecimento evidenciado para a captura e construção das artes de pesca, que já não está sendo transmitido aos descendentes. Assim, constata-se o processo de marginalizaçáo e as consequentes mudanças na utilização e construção dos aparelhos de pesca e os riscos do desaparecimento dessa atividade nos próximos anos.

Palavras-chave: Conhecimento Tradicional, Etnoecologia, Lagoa Mundaú, Pescas, Nordeste do Brasil.

\section{ABSTRACT}

One of the major issues in ethnobiology is the quality of life of coastal communities who traditionally survive by artisanal fishing. Due to uncontrolled exploitation of fisheries resources and irregular urban sprawl, fishing in estuaries and mangroves is undergoing widespread decline. A good example is the Mundau Lagoon, Alagoas state, northeast Brazil, part of a highly productive estuarine complex where fishing is a vital component of livelihoods of many communities, including the village of Fernão Velho. This lagoon has been affected by different anthropogenic activities that have reduced fish stocks and negatively impacted the social and economic conditions of the surrounding communities. The present study assesses the current state of fisheries in Fernão Velho. The study was conducted between June 2007 and November 2012, through open and semi-structured interviews, observations and photographic records. Fishermen were selected by a snowball sampling technique. The results indicate that about $95 \%$ of the respondents have low levels of education. Young people do not aspire to become fishers, being enrolled in public schools or developing other activities. Thus, the culture of artisanal fishing is no longer being transmitted to the new generation, potentially leading to its eventual disappearance. Current fishing vessels include canoes, boats and vogue boats. Between fish attractor are the caiçaras e pitimboiias, little used today. Fishing methods includes gillnetting, casting net, shrimp traps and jereré, beyond reducho and fishing beat, classified as illegal methods. Despite the decline of fish stocks in the Mundaú lagoon, Fernão Velho still harbors a community of traditional fishermen with considerable knowledge about the construction and use of fishing gear, as well as detailed information about the ecological state of the local fish fauna.

Keywords : Traditional Knowledge, Ethnoecology, Mundaú Lagoon, Fisheries, northeast of Brazil

@ - Corresponding author

1 - Universidade Federal de Alagoas, Programa de Pós-Graduação Diversidade Biológica e Conservação nos Trópicos, Av. Lourival Melo Mota, s/nº, Tabuleiro do Martins 57072-900 - Maceió, AL, Brasil.e-mail: everson_ufal@yahoo.com.br

2 - Universidade Federal de Alagoas, Unidade de Ensino Penedo. Av. Beira Rio, s/nº, Centro Histórico, 57.200-000, Penedo, AL, Brasil. e-mail: buiabahia@gmail.com

* Submission: 11 July 2012; Evaluation: 25 August 2013; Reception of revised manuscript: 25 November 2013; Accepted: 27 November 2013; Available on-line: 12 December 2013 


\section{INTRODUÇÃO}

Uma das grandes questôes discutidas no âmbito da etnobiologia relaciona-se com a qualidade de vida de comunidades que tradicionalmente sobrevivem dos recursos pesqueiros explorados em áreas de lagoas e estuários (Marques, 1991; Barros et al., 2000; Costa-Neto \& Marques, 2001; Alves \& Nishida, 2003; Nascimento \& Sassi, 2007; Ramires et al., 2012; Lima \& Velasco, 2012). Os estuários estão entre os mais produtivos e complexos ecossistemas costeiros do mundo e têm sido um dos ambientes mais favoráveis à ocupação humana, pois agrupam a disponibilidade de água doce e alimentos e a facilidade de transporte (Costa, 1980; Duarte \& Vieira, 1997; Reis \& D'incao 2000; Diegues, 2001; Mendonça \& Katsuragawa, 2001; Elliot \& Mclusky 2002; Alves et al., 2009, Gianesella \& Saldanha-Corrêa, 2010).

Nesse contexto, a pesca artesanal desenvolvida em região estuarina exerce um relevante papel no contexto econômico e social de comunidades tradicionais, tornandose fundamental para a subsistência dos pescadores e de suas famílias (Barros etal., 2000; Souza \& Neumann-Leitão, 2000; Costa-Neto, 2001; Alves \& Nishida, 2003; Nascimento \& Sassi, 2007; Silva et al., 2007; Ramires et al., 2012; Lima \& Velasco, 2012). O contato diário dos pescadores com o ambiente natural assegura um conhecimento acurado quanto à classificação, ao comportamento, à biologia e à utilização dos recursos naturais da região onde vivem (Paz \& Begossi, 1996; Silvano, 1997; Souza \& Barrella, 2001; Mourão \& Nordi, 2003; Fadigas \& Garcia, 2012), gerando informaçóes importantes que podem subsidiar diferentes ações de pesquisa, conservação e manejo dos estoques pesqueiros (Calheiros et al., 2000; Diegues, 2003; Silvano et al., 2008; Porcher et al., 2010; Rosa et al., 2011; ; Fadigas \& Garcia, 2012).

Estudos desenvolvidos nas últimas décadas têm revelado que a pesca artesanal, principalmente a desenvolvida em áreas urbanas, é alvo de problemas ambientais decorrentes, principalmente, da pressão da urbanização irregular, o que tem comprometido a transferência do conhecimento tradicional (Melo-Magalhães et al., 2009; Silva \& Souza 2009; Souza \& Neumann-Leitão, 2000; Junior, 2010; Araujo et al., 2011; Ferreira, 2011; Osório et al., 2011; Pedrosa et al., 2013). Nas comunidades urbanas da cidade do Recife (PE), Nordeste do Brasil, os pescadores artesanais resistem à crescente urbanização e convivem de perto com a exclusão social, realizando suas atividades, na maioria das vezes, em estuários degradados (Pedrosa et al., 2013).

Entre as principais açôes antropogênicas que impactam os ecossistemas estuários estão a introdução de espécies invasoras, a pesca predatória e a poluição por esgotos de diversas origens, que contribuem para a diminuição da diversidade e da estabilidade desse ambiente (Reis \& D'incao, 2000; Suhogusoff \& Piliackas, 2007; Troca \& Vieira, 2012). Além disso, problemas técnicos e sociais, como a longa jornada de trabalho, o consumo excessivo de bebidas alcoólicas e entorpecentes e casos de enfermidades, têm contribuído para a precarização da pesca artesanal e para a desorganização do modo de vida em muitas comunidades (Souza \& Neumann-Leitão, 2000; Nascimento \& Sassi 2007; Correia et al., 2008, Pena et al., 2011; Rios et al., 2011; Lima \& Velasco, 2012).
O Complexo Estuarino-Lagunar Mundaú-Manguaba (CELMM) é uma das mais importantes áreas úmidas da costa nordeste do Brasil, apresentando grande relevância histórica, turística, cultural, biológica e pesqueira (Costa, 1980; Silva \& Pereira-Barros, 1987; Teixeira \& Falcão, 1992; Teixeira \& Sá, 1998; Correia \& Sovierzoski, 2009). Porém, há cerca de três séculos, o CELMM sofre impactos de diversas origens, como o lançamento de esgotos domésticos e industriais não tratados, assoreamento, ocorrência de cheias e urbanização irregular (Marques, 1991; Agência Nacional de Águas, 2006; Melo-Magalhães et al., 2009; Silva \& Souza 2009). Além disso, a pesca ilegal, associada ao aumento da pressão pesqueira para atender às necessidades alimentares da população crescente, tem contribuído para o declínio dos estoques nativos, afetando o modo de vida nas comunidades banhadas pelas lagoas Mundaú e Manguaba (Costa, 1980; Marques, 1991; Agência Nacional de Águas, 2006).

Estudos etnoecológicos têm fornecido dados importantes sobre as experiências práticas vivenciadas pelos pescadores artesanais e como estes respondem adaptativamente às mudanças ambientais, causadas, principalmente, pela expansão urbana irregular (Berkes et al., 1998; CostaNeto, 2001). Contudo, o desenvolvimento de estudos em áreas urbanas é difícil, devido à frequente confusão entre pesquisadores e agentes da fiscalização ambiental, sendo comuns as relações de desconfiança (Alves \& Souto, 2010).

O presente trabalho registra o processo de marginalizaçáo da pesca artesanal em Fernão Velho, comunidade localizada na malha urbana da cidade de Maceió-AL, às margens da Lagoa Mundaú. Com isso, os objetivos deste estudo foram i) avaliar as condiçóes socioeconômicas dos pescadores artesanais de Fernão Velho, ii) descrever as tecnologias de pesca utilizadas e iii) determinar o estado atual da ictiofauna.

\section{MATERIAL E MÉTODOS}

\section{1. Área de Estudo}

A lagoa Mundaú está situada no litoral médio do Estado de Alagoas (Figura 1), abrangendo os municípios de Maceió, Coqueiro Seco, Santa Luzia do Norte, Pilar e Marechal Deodoro. Possui uma área de aproximadamente $27 \mathrm{~km}^{2}$, profundidade entre 2 e 7 metros e está inserida na bacia hidrográfica do rio Mundaú, com nascente próxima à cidade de Garanhuns/PE (Agência Nacional de Águas, 2006). Desde sua nascente, a lagoa Mundaú recebe efluentes de diferentes indústrias sucroenergéticas; além disso, a favelização de áreas marginais e a falta de saneamento básico dos assentamentos humanos estão entre os principais fatores degradantes do ambiente (Silva \& Souza, 2009).

A lagoa Mundaú está interligada à lagoa Manguaba por uma rede de canais, originando o Complexo Estuarino Lagunar Mundaú-Manguaba (CELMM), ecossistema rico e abundante em recursos pesqueiros, onde o sururu (Mytella falcata Orbigny, 1846) é usado para preparar o prato típico da região e representa o maior volume de produção pesqueira (Marques et al., 1993). Diversos autores descreveram com maior detalhe o CELMM; dentre eles, destacam-se Costa (1980), Marques (1991) e Correia \& Sovierzoski (2009).

A comunidade de Fernão Velho está localizada a noroeste da cidade de Maceió, em uma estreita planície 
entre a lagoa Mundaú, ao sul, e a região de tabuleiro, ao norte. Fernão Velho é uma antiga vila operária fundada em 1857 , oriunda da instalação da primeira indústria têxtil de Alagoas (Sant'Ana, 1970) e construída nos moldes das cidades industriais europeias (Sarmento, 2002). Porém, devido aos baixos salários recebidos pelos operários, a pesca artesanal tornou-se uma das principais atividades, fazendo dessa comunidade um importante ponto de desembarque pesqueiro (Farias, 2012).

Atualmente, Fernão Velho está inserida na Área de Proteção Ambiental (APA) do Catolé e Fernão Velho, criada pelo Decreto Estadual $n^{\circ}$. 5.347/1992, definida como uma regiāo composta por floresta ombrófila, manguezais e diversos mananciais (Alagoas, 1992). Sua escolha como área de trabalho ocorreu: (i) por sua localização, uma vez que se desenvolveu na margem da lagoa Mundaú; (ii) por estar parcialmente isolada de bairros adjacentes e (iii) pelo potencial acúmulo de conhecimentos etnoecológicos da população local, que explora os recursos naturais da lagoa há várias geraçôes.

\section{METODOLOGIA}

O trabalho desenvolveu-se entre junho de 2007 e novembro de 2012, quando foram realizadas 15 saídas de campo para a coleta de informações na comunidade de Fernão Velho, seguindo os seguintes métodos quali-quantitativos: (i) entrevistas livres, (ii) semiestruturadas, (iii) observaçóes diretas, (iv) registros fotográficos.

Inicialmente, foram realizadas 25 entrevistas livres individuais, em que o número de pescadores cadastrados na colônia Z-04 serviu como base para delimitar o universo amostral dos entrevistados. Nessa colônia, estão cadastrados 78 pescadores artesanais de Fernão Velho, que atuam preferencialmente na lagoa Mundaú. Durante as entrevistas livres, foram colhidas informaçóes sobre o perfil socioeconômico dos pescadores entrevistados e as condiçóes da pesca na regiáo. Tais entrevistas serviram, também, como geradoras de confiança entre entrevistador e entrevistado.

A partir das entrevistas livres, os 15 pescadores mais experientes de Fernão Velho (i.e. há mais tempo engajados nas atividades pesqueiras) foram identificados e submetidos a

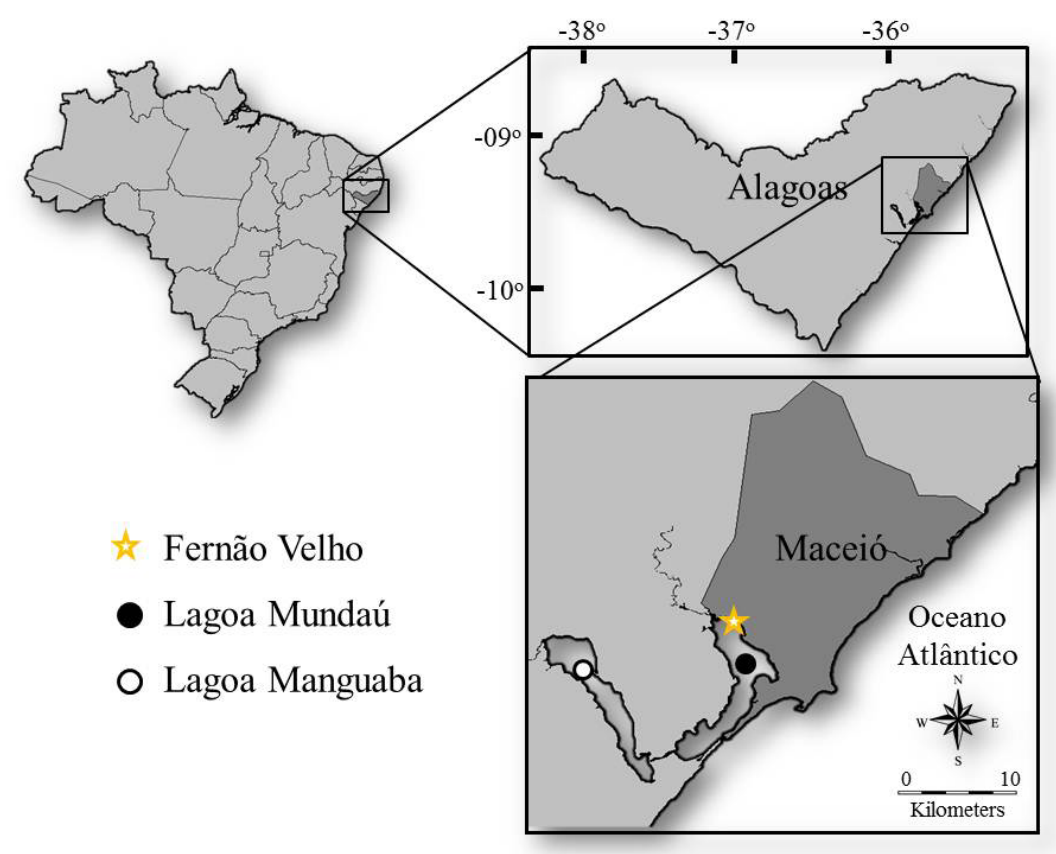

Figura 1. Mapa indicando a localização da Lagoa Mundaú e a comunidade de Fernão Velho, Maceió, Alagoas.

Figure 1. Map showing the location of Mundaú lagoon and community Fernão Velho, Maceió, Alagoas. 
entrevistas semiestruturadas baseadas em questionários, com o objetivo de coletar as melhores informaçóes possíveis. As perguntas norteadoras foram relacionadas, principalmente, com a utilização de embarcaçóes, atratores e apetrechos de pesca e com o estado atual da ictiofauna.

Para a seleção dos pescadores para as entrevistas, foi utilizada a técnica de amostragem snowball sampling (Biernacki \& Waldorf, 1981; Gabor, 2007; Pieve et al., 2009). Nesse método, cada entrevistado, ao final de sua entrevista, indica outro pescador artesanal da comunidade para entrevistas posteriores, e assim sucessivamente, até que os pesquisadores tenham abrangido a maior parte possível dos pescadores indicados (Penrod et al., 2003). Esse método não probabilístico tem vindo a ser considerado um dos mais adequados métodos de recrutamento de sujeitos pertencentes a populaçóes ocultas ou dispersas, como é o caso dos pescadores urbanos de Fernáo Velho (Penrod et al., 2003; Wright \& Stein, 2005). A cadeia de entrevistas foi iniciada com o pescador e presidente da associação dos pescadores de Fernão Velho (N.S.N., 55 anos), reconhecido pela comunidade como pescador experiente, e as entrevistas foram realizadas de forma individual.

As espécies de peixes citadas durante as entrevistas foram adquiridas através de compras e doaçóes dos pescadores locais e foram conduzidas ao Laboratório de Ictiologia da Universidade Federal de Alagoas - Unidade de Ensino Penedo. Em laboratório, os espécimes foram fotografados e determinados com auxílio de bibliografia especializada (Costa, 1980, Sampaio \& Nottingham, 2007; Garcia-Jr et al., 2010), fixadas em formalina a $10 \%$ e, posteriormente, conservadas em álcool $70 \%$.
Para as análises quantitativas dos dados, foram utilizados os percentuais de respostas dos 25 informantes entrevistados. Para verificar as condiçóes atuais da pesca artesanal, foi utilizado o método qualitativo, efetuado por meio da interpretaçáo do discurso dos entrevistados e, sempre que possível, as respostas dos informantes foram comparadas com trabalhos científicos (Mourão \& Nordi, 2003; Diegues, 1983; Mourão, 2003; Burns et al., 2006, Pieve et al., 2009).

\section{RESULTADOS E DISCUSSÃO}

\subsection{Os pescadores de Fernáo Velho}

A atividade de pesca desenvolvida pela comunidade de Fernão Velho é artesanal e caracteriza-se pelo trabalho familiar, no qual os homens são predominantes e atuam, principalmente, na captura do pescado, enquanto o beneficiamento de moluscos, crustáceos e a salga dos peixes são realizados tipicamente pelas mulheres. Cerca de $40 \%$ dos entrevistados comercializam sua produção localmente, enquanto os outros praticam a pesca de subsistência. Essa realidade local está de acordo com dados apresentados em outros trabalhos que identificam a pesca artesanal no Brasil como uma atividade predominantemente masculina (Condini et al., 2007; Silva et al., 2007; Porcher et al., 2010; Lima \& Velasco, 2012), enquanto o beneficiamento de peixes e mariscos é uma atividade comumente associada às mulheres (Di Ciommo, 2007; Martins, 2008; Lima \& Velasco, 2012; Walter et al., 2012). Em Fernão Velho, a pesca artesanal é desenvolvida predominantemente por pescadores adultos, com baixo nível de instrução e com diferentes fontes de renda e tempo de pesca (Tabela 1).

Tabela 1. Perfil socioeconômico dos pescadores artesanais entrevistados em Fernão Velho, Maceió, AL.

Table 1. Socio-economic profile of the artisanal fishermen's interviewed in the Fernão Velho, Maceio, AL.

\begin{tabular}{|c|c|}
\hline Informaçóes & Resultados (n=25) \\
\hline Faixa etária dos informantes & $\begin{array}{l}\text { Idade mínima: } 27 \text { anos } \\
\text { Idade máxima: } 72 \text { anos } \\
\text { Idade média: } 48 \text { anos }\end{array}$ \\
\hline Tempo de pesca & $\begin{array}{l}\text { Até } 10 \text { anos: } 22 \% \\
\text { Entre } 11 \text { e } 30 \text { anos: } 48 \% \\
\text { Entre } 31 \text { a } 51 \text { anos: } 17 \% \\
\text { Acima de } 51 \text { anos: } 13 \%\end{array}$ \\
\hline Origem dos pescadores & $\begin{array}{l}\text { Fernão Velho: } 45 \% \\
\text { Outros locais: } 55 \% \\
\text { - } \quad \text { Outros bairros de Maceió: } 35 \% \\
\text { - } \quad \text { Outros municípios de Alagoas: } 60 \% \\
\text { - } \quad \text { Outros Estados do Brasil (Goiás e Pernambuco): } 5 \%\end{array}$ \\
\hline Escolaridade & $\begin{array}{l}\text { Analfabetos: } 45 \% \\
\text { Fundamental incompleto: } 50 \% \\
\text { Ensino médio completo: } 5 \%\end{array}$ \\
\hline Estado civil & Casados: $61 \%$ \\
\hline Outras fontes de renda & $\begin{array}{l}\text { Aposentado: } 26 \% \\
\text { Servente de Pedreiro: } 26 \% \\
\text { Vigilante: } 21 \% \\
\text { Outros: } 27 \%\end{array}$ \\
\hline
\end{tabular}


O baixo nível de instrução observado parece ser uma tendência na pesca artesanal, não sendo uma exclusividade das regiōes suburbanas. Diversos autores também observaram baixos níveis de escolaridade em outras comunidades pesqueiras no Nordeste do Brasil (Souza \& NeumannLeitão, 2000; Nishida et al., 2008a; Nascimento \& Sassi, 2007; Alencar \& Maia, 2011). A idade em que os pescadores iniciaram suas atividades na pesca pode justificar o baixo nível de escolaridade deles, já que a necessidade de contribuir com a renda familiar, a incompatibilidade entre os horários da pesca e da escola e a falta de estímulo para estudar podem influenciar nos índices de evasão escolar (Nishida, 2008a; Vieira et al., 2013).

Apesar desses fatos, atualmente, há grande preocupação entre os entrevistados quanto à educação formal de seus filhos, estando quase todos devidamente matriculados em escolas públicas, muitos com nível de escolaridade superior ao dos pais. Esse fato pode estar relacionado à atual política de inclusão social do governo federal brasileiro e também ao cumprimento da legislação brasileira, que está punindo os pais ou responsáveis pela negligência na educação dos filhos (Art. 246 do Código Penal - Decreto Lei 2.848/40; Art. 22 e 55 do Estatuto da Criança e do Adolescente - Decreto Lei 8.069/90; Art. 1.634 do Código Civil - Decreto Lei 10.406/02).

Cerca de 30\% dos entrevistados aprenderam a pescar com seus familiares, porém não desejam que seus filhos sejam pescadores, pois alegam que a pesca não assegura um futuro promissor. A atividade pesqueira também não está garantindo a subsistência digna dos pescadores e de suas famílias, fazendo com que esses busquem outras atividades. Fatos similares foram observados por Nascimento \& Sassi (2007) em Cajueiro da Praia (PI) e Lima \& Velasco (2012) em comunidades do estuário da Lagoa dos Patos (RS). Quando foi perguntado aos entrevistados se eles gostariam que seus filhos se tornassem pescadores, as respostas deixam evidente que os componentes culturais contidos na comunidade estáo deixando de ser transmitidos para as novas geraçôes, como podemos perceber em trechos das entrevistas.

"Não... porque a lagoa tá sem futuro pros jovens, eles tem mesmo é que estudar e seguir outro ramo" [sic] (J.A.T., 55 anos)

"... só se fosse pescador em outro canto, aqui nessa lagoa (Mundaú) não tem futuro pra ninguém" [sic] (A.P.C., 63 anos)

Na cidade de Maceió (AL), parte da população de baixa renda habita áreas marginais e ambientalmente frágeis. Em Fernão Velho, muitas residências estão localizadas em zonas de deslizamentos e inundaçôes (Melo \& Lins, 2010). Cerca de $75 \%$ dos entrevistados possuem casa própria, construída em alvenaria $(95 \%)$ ou taipa (5\%), onde a ausência de saneamento básico e a deficiência na coleta do lixo favorecem o lançamento desses resíduos no ambiente aquático, um dos principais fatores de poluição na regiấo (Marques, 1991; Araújo et al., 2011). As condiçóes socioambientais e sua implicação na atividade pesqueira podem ser evidenciadas nos relatos dos informantes.

"... Antigamente era menos pescador e mais peixe, hoje tem muita gente que mora na beira da lagoa, muita gente pescando e não respeita mais a natureza, joga o lixo dentro d'água, é garrafa, sacolas plásticas, esgoto e até bicho morto. Além disso, hoje é mais fácil comprar rede, toda loja vende, e antigamente era a gente quem fazia tudo". [sic] (A.N.C., 45 anos)

Em meados da década de 1980 , cerca de $50 \%$ da população de Fernão Velho e comunidades adjacentes viviam em função dos recursos oriundos da lagoa Mundaú (PereiraBarros \& Pereira-Barros, 1987; 1988). Porém, com a intensa modificação da paisagem natural, sobretudo nos últimos 30 anos, houve uma redução da vegetação nativa e dos estoques pesqueiros (PLEC, 1980; Marques, 1991; Silva \& Souza, 2009), refletindo diretamente na socioeconomia das comunidades localizadas no entorno do CELMM. Enquanto muitos desempregados ingressam na atividade pesqueira, boa parte dos pescadores tradicionais e seus descendentes já não se orgulham nem veem atrativos na atividade. Essa situação aponta na direção não só da marginalização da atividade, mas também do perigo de extinção enquanto atividade tradicional (Ferreira, 2011).

\subsection{As embarcaçóes utilizadas}

O município de Maceió contém cerca de $20 \%$ do total de embarcaçôes do Estado de Alagoas, dentre as quais as canoas representam o maior número (63\%) da frota (IBAMA/ SEAP/PROZEE, 2008). Em Fernão Velho, cerca de 70\% dos informantes possuem pequenas embarcaçóes, que podem ser de três tipos: canoa (22\%), barco $(61 \%)$ ou barco de voga (17\%) (Figura 2).

As canoas utilizadas em Fernão Velho (Figura 2a) são construídas com uma única tora de jaqueira (Artocarpus heterophyllus Lamarck) ou visgueiro (Parkia pendula (Willd.) Benth. ex Walp.) escavada, apresentando dimensões que variam de 6 a $8 \mathrm{~m}$ de comprimento e 0,7 a $0,8 \mathrm{~m}$ de boca, semelhantes às descritas por Chaves \& Robert (2003) e Nishida et al. (2008b). Por terem maior estabilidade e durabilidade, possuem grande importância econômica e cultural quando comparadas com as outras embarcaçóes locais. A eliminação da Mata Atlântica e a consequente criação da APA do Catolé e Fernão Velho, que proibiu a extração de árvores, levou a uma alta nos preços das canoas (PLEC, 1980), sendo estas gradativamente substituídas por outras embarcações.

$\mathrm{Na}$ categoria barco (Figura 1b), incluem-se as embarcaçôes construídas com tábuas de madeira industrializadas e encaixadas, com dimensóes que variam de 6 a $7 \mathrm{~m}$ de comprimento e 0,8 a $1,2 \mathrm{~m}$ de boca, as quais são movidas a remos, velas ou motores. São as mais utilizadas na comunidade, recebendo também as denominaçôes de "bote" (Chaves \& Robert, 2003; Nishida et al., 2008b) ou "bote de casco" (IBAMA/SEAP/PROZEE, 2008).

O barco de voga (Figura 1c), conhecido localmente por tilapeiro, é uma pequena embarcação construída com tábuas de madeira industrializadas, com dimensōes que variam de 2,5 a $4,5 \mathrm{~m}$ de comprimento e 0,5 a $1 \mathrm{~m}$ de boca, e propelida a vela ou utilizando-se dois remos fixados nas bordas da embarcação, onde os pescadores trabalham sentados. Essa embarcação é originária da região agreste de Alagoas e foi inserida na Lagoa Mundaú em meados da década de 90 do século passado por duas famílias de Fernão Velho, que as constroem e utilizam. Essas famílias possuem uma frota de quatro embarcaçóes utilizadas para a captura de peixes, em especial tilápia (Oreochromis niloticus Linnaeus, 1758), espécie exótica. 

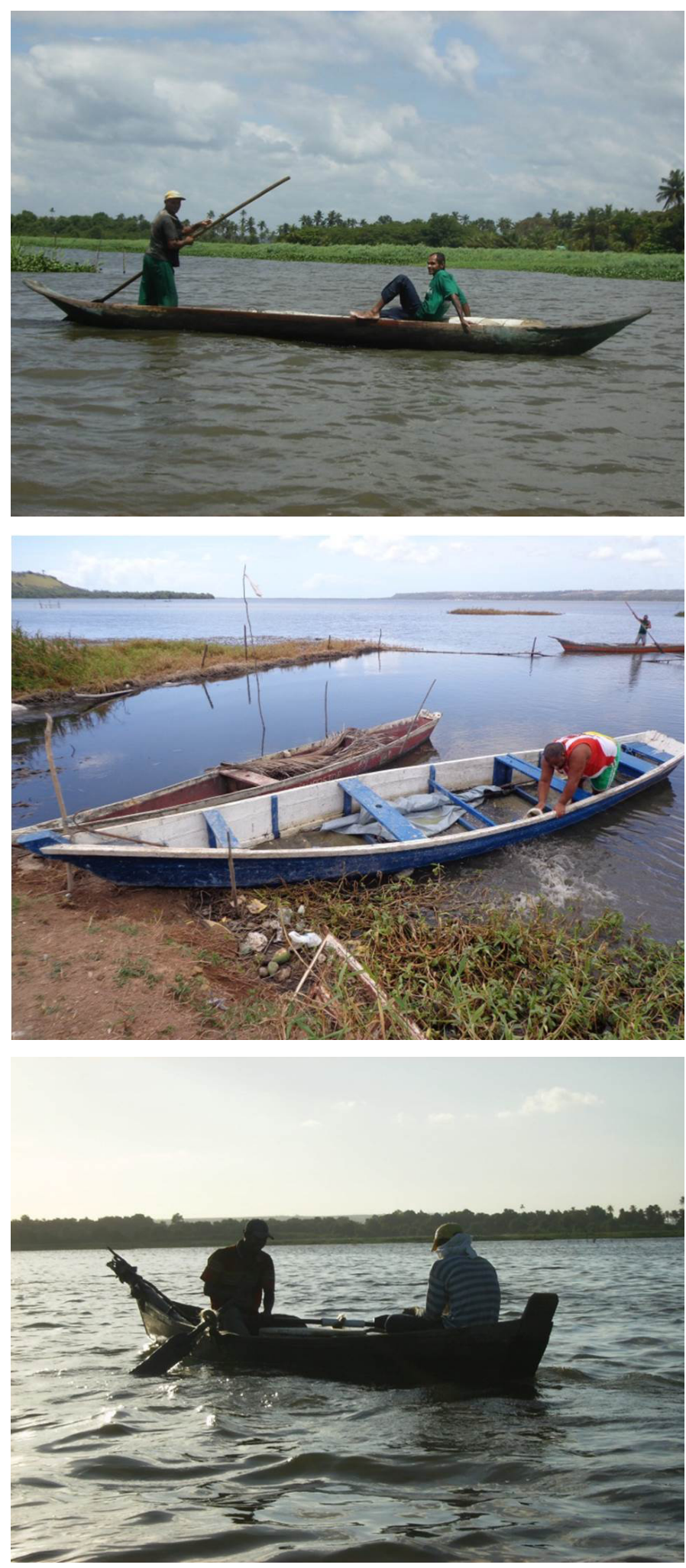

Figura 2. Tipos de embarcaçóes utilizadas pelos pescadores de Fernão Velho, Maceió, Alagoas: (a) canoa, (b) barco e (c) barco de voga.

Figure 2. Types of boats used by fishermen in Fernão Velho, Maceió, Alagoas: (a) canoa (b) barco (c) barco de voga.
Atualmente, as canoas são construídas, muito embora raramente, na comunidade de Coqueiro Seco, município localizado na margem leste da Lagoa Mundaú, enquanto os barcos são construídos em Fernão Velho, sendo semelhantes às embarcaçóes empregadas em outros ambientes estuarinos da região Nordeste (Costa-Neto \& Marques, 2001; Nishida et al., 2008b, Cintra et al., 2009) e, independentemente do tamanho, conduzem, em média, dois tripulantes por viagem.

\subsection{Os atratores de pesca}

A prática de colocar ramos e galhos de plantas para atrair peixes e crustáceos é muito comum em diversas partes do mundo (Marques, 1991). No Brasil, diversas comunidades utilizam diferentes tipos de atratores de pesca, como as galhadas (Cardoso, 2008), marambaias (Nascimento, 2006), caiçaras (Legendre, 1985; Nogueira \& Sassi, 2007) e pitimbóias (Legendre, 1985), os quais disponibilizam alimento e/ou abrigo para diversas espécies de interesse pesqueiro (Marques, 1991; Nogueira \& Sassi, 2007). Na lagoa Mundaú, os atratores tradicionais de pesca utilizados são as caiçaras e pitimbóias.

As caiçaras (Figura 3) são agrupamentos de ramos e galhos, com diferentes formatos e tamanhos, colocados em lagoas ou estuários, um atrativo para muitas espécies de peixes que buscam abrigo e alimento (Legendre, 1985). No Brasil, os registros de caiçaras mais detalhados são do litoral alagoano, mais especificamente no CELMM (Marques, 1991; Nogueira \& Sassi, 2007), onde Legendre (1985) descreveu suas formas em "circulares" e "retangulares", enquanto Nogueira \& Sassi (2007) classificaram seus tipos em "submersas" e as "que afloram na superfície".

As pitimbóias (Figura 4) são pequenos atratores confeccionados pelos pescadores locais. Para a sua construção, são utilizadas folhas de ouricuri (Arecaceae), ramos de mangueira (Anacardiaceae) e vegetação típicas do manguezal (Avicennia sp., Laguncularia sp. ou Rhizophora sp.), todos amarrados com um cabo (denominado de "ligeira") a uma estaca vertical ("mourāo") fixada no substrato.

As pitimbóias são, geralmente, instaladas em série (normalmente entre 20 e 100), principalmente durante o inverno, quando passam pelos processos de "encharque", flutuando por cerca de três dias, até submergirem e entrarem no processo de "captura", no qual são despescadas com um jereré, manuseado por um pescador embarcado, são trazidas para a superfície e agitadas vigorosamente para a captura de siris e camarôes (Legendre, 1985, Obs. Pess.).

Atualmente, a utilização de atratores pelos pescadores de Fernão Velho é rara, principalmente a caiçara. Muitos pescadores alegaram que já não podem cortar galhos de árvores por se tratar de uma área protegida (Área de Preservação Ambiental Catolé e Fernáo Velho), outros afirmam que a quantidade e o tamanho dos peixes já não compensam a sua construção e despesca, mostrando-se desmotivados para a confecção e utilização desses atratores. Nogueira (2005) relata a tendência ao seu desaparecimento, pois os filhos e netos dos pescadores artesanais exercem preferencialmente outras profissōes, não recebendo as devidas orientaçōes sobre as técnicas de construção e os locais de instalação desses atratores. 


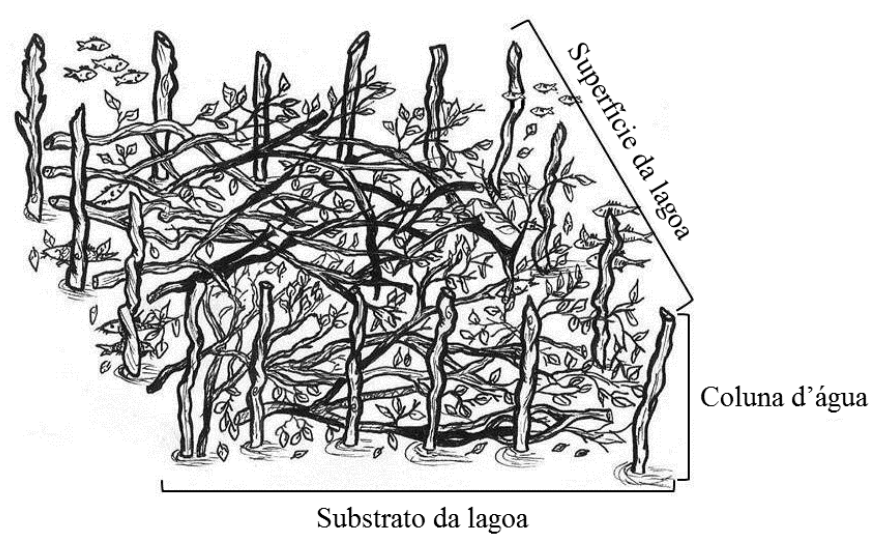

Figura 3. Caiçara retangular construída na Lagoa Mundaú para atrair peixes e crustáceos.

Figure 3. Caiçara rectangular built in Mandaú lagoon to attract fish and crustaceans.

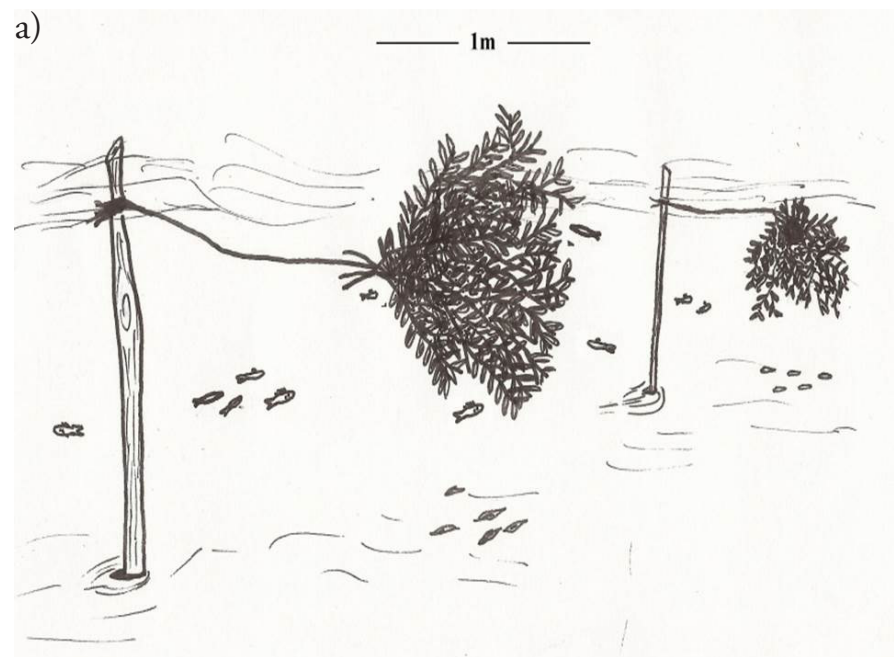

b)

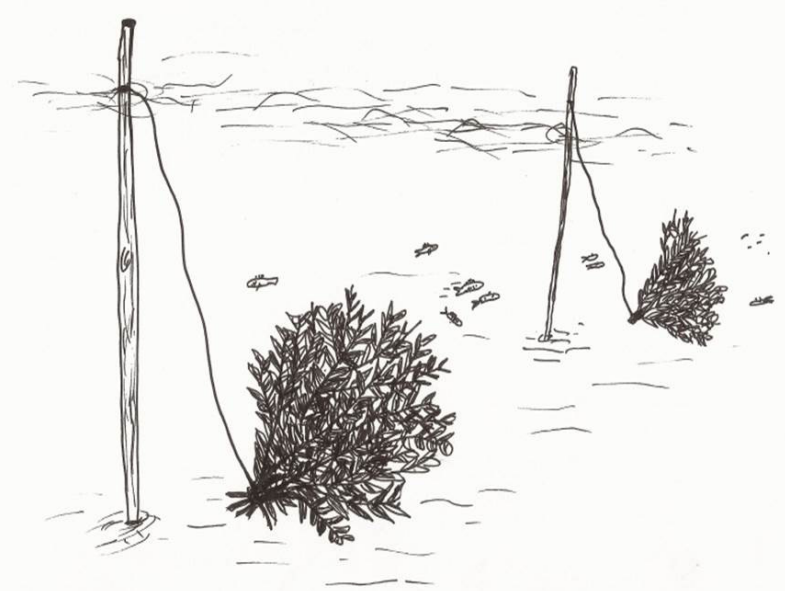

Figura 4. Pitimbóias utilizada pelos pescadores de Fernão Velho, Maceió-AL, para a captura de siris e camarão; (a) processo de encharque, (b) processo de captura.

Figure 3. Pitimbóias used by Fernão Velho fishermen's, Maceió-AL, for catching crabs and shrimps; (a) soaking process, (b) capture process.

\subsection{Os apetrechos de pesca}

Entre os apetrechos e as técnicas mais utilizadas pelos pescadores de Fernão Velho, destacam-se as redes de espera e covos (apetrechos passivos); tarrafas, jererés e reduchos (apetrechos ativos). O sucesso de captura com os apetrechos passivos depende do comportamento ativo das espécies-alvo, enquanto os métodos ativos capturam pela movimentaçáo do apetrecho, praticamente à revelia de seu comportamento (Catella, 2007).

A rede de espera destaca-se por ser o apetrecho mais utilizado, sendo denominado na região de "pesca de minjuada". São redes com cerca de $2 \mathrm{~m}$ de altura e comprimento variável, dispostas verticalmente na coluna d'água por uma série de bóias (de isopor) na parte superior, e chumbo ou cabo chumbado na parte inferior. A espessura do nylon e o tamanho da malha irão depender das espéciesalvo. A rede de espera é colocada, geralmente, durante o dia, ficando submersa entre 8 e 12 horas, sendo responsável pela captura de diversas espécies de peixes, como: tainhas e curimãs (Mugilidae), carapebas (Gerreidae), camurins (Centropomidae), bagres e mandins (Ariidae), mororós (Gobiidae) e tilápias (Cichlidae), esta última introduzida.

O covo é uma armadilha semifixa, confeccionada com a raque das folhas da palmeira ouricuri (Arecaceae), telas de plástico ou arame, que possui um formato cilíndrico com duas entradas afuniladas, uma em cada base, e uma porta lateral. Possui de $0,3 \mathrm{~m}$ a $0,5 \mathrm{~m}$ de comprimentos e 0,15 $\mathrm{m}$ a $0,2 \mathrm{~m}$ de diâmetro e é colocado em série no fundo da lagoa, onde crustáceos (camarôes e siris) e eventualmente pequenos peixes sáo atraídos por iscas, geralmente pedaços de coco seco, macaxeira ou peixes. Armadilhas semelhantes são utilizadas em vários lugares do Brasil e do mundo, e.g. Baixo São Francisco (Montenegro et al., 2007); no litoral norte da Bahia (Costa-Neto, 2001; Costa-Neto \& Marques, 2001) e em comunidades distantes como os polinésios, na Micronésia (Lieber, 1994).

A tarrafa é uma rede circular guarnecida de chumbo na borda e um cabo (fiel) que parte do centro da rede, tendo a função de puxar o petrecho. É utilizada, principalmente, para a captura de peixes. É pouco utilizada localmente, pois o substrato da regiáo próxima à comunidade contém galhos oriundos de pitimbóias e caiçaras abandonadas, o que geralmente danifica o apetrecho.

O jereré é construído com varas de imbiribeiro (Lecythidaceae) ou jenipapeiro (Rubiaceae), uma delas em formato semicircular (arco) com cerca de 1,5m de diâmetro, onde se prende uma rede de nylon em forma de saco, com malhas entre $8 \mathrm{~mm}$ e $15 \mathrm{~mm}$, e um cabo para ser manejado durante a despesca das pitimbóias. É também utilizado nas margens da lagoa, para a captura de organismos bentônicos, como camaróes, siris e pequenos peixes.

O reducho é uma pequena rede, com aproximadamente $4 \mathrm{~m}$ de comprimento, $1,5 \mathrm{~m}$ de altura e malha que varia entre $7 \mathrm{~mm}$ e $15 \mathrm{~mm}$ entre nós opostos; em cada extremidade, prende-se uma vara a qual é arrastada por dois pescadores, geralmente em águas rasas, inferiores a 1,5 m. Trata-se de um arrasto de fundo, no qual a malha fina é de uso proibido (Art. 113 do Código de Caça e Pesca - Decreto no 23.672/34). Apesar dos fatos, é muito utilizado pelos pescadores de 
Fernão Velho para a captura de camarôes, siris e pequenos peixes.

Outra prática ilegal e bastante utilizada é a "pesca de batida" (Art. 26 do Código de Caça e Pesca - Decreto no 23.672/34), que consiste em colocar uma rede (semelhante à rede de espera) ao redor de caiçaras, ilhas de vegetação ou margens de manguezal e, em seguida, realizar a batida na água com uma vara (denominada de "macete" ou "martelo"), feita de mangue, simulando o efeito de uma explosão e assustando os peixes, que se deslocam, indo de encontro à rede. Todavia, mesmo reconhecendo sua proibição, é realizada regularmente para a captura de diversas espécies de peixes, em especial a tilápia, bastante apreciada localmente.

Para garantir o uso sustentável dos recursos naturais no CELMM, medidas de restrição pesqueira foram adotadas, como a restrição de algumas estratégias de pesca consideradas predatórias. Enquanto alguns pescadores se adequaram às normas, aumentando o esforço de pesca, mudando suas estratégias de captura e/ou buscando outras fontes de renda, muitos infringem as leis ambientais vigentes para assegurar o seu sustento.

"O reducho é uma pescaria que pega muito peixe pequeno, já a pesca de batida espanta os peixes e os malham na rede. Esses tipos de pescaria pega toda a filiação (alevinos) dos peixes, do siri e do camarão. Eu pesco e vendo como isca".[sic] (J.A.T., 55 anos).

\subsection{A ictiofauna}

A riqueza de espécies na lagoa Mundaú é relativamente bem conhecida. Para o CELMM, Costa (1980) registrou 53 famílias e 95 espécies; Marques (1991), cerca de 80 espécies, e Teixeira e Falcão (1992) registram 39 famílias e 86 espécies de teleósteos demersais. Durante as entrevistas, foram registradas 41 etnoespécies (variedades, segundo o nome popular) de peixes.

Entre as citadas, destacam-se a tainha (Mugil liza Valenciennes, 1836), o curimã (Mugil curema Valenciennes, 1836) e o boca de cavalo (Anchovia clupeoides Swainson, 1839), por apresentarem alto valor comercial. Em 2008, a tainha foi a espécie de maior importância nos desembarques para o Estado de Alagoas, com cerca de $2.500 \mathrm{t}$ anuais (IBAMA/SEAP/PROZEE, 2008). Porém, mesmo sendo consideradas abundantes na lagoa Mundaú, percebe-se no discurso dos entrevistados que, ao longo do tempo, houve reduçáo na produção pesqueira:

(...) o peixe tá se acabando, mas tainha e curimã ainda tem muita, a gente sempre pega, mas não como antes. Hoje a gente pega de 10 a $15 \mathrm{~kg}$ de tainha em uma semana, antigamente era $10 \mathrm{~kg}$ em um lance de minjuada, mas em comparação com os outros peixes, tem muita. [sic] (J.B., 68 anos)

Já o mandim (Cathorops spixii Spix \& Agassiz, 1829), o mororó (Gobionellus oceanicus Pallas, 1770) e o morongo (Gobioides broussonnetii Lacepède, 1800) são espécies de baixo valor de mercado, todavia de grande valor social, pois são acessíveis à comunidade de baixa renda, sendo, muitas vezes, comercializados secos e salgados. O mandim é o peixe mais comum da lagoa Mundaú. Costa (1980) relatou ocasióes em que esse peixe chegou a aborrecer os pescadores, que veem suas redes repletas pelo referido peixe, tendo que abandonar a pescaria para desmalhá-los.
Digna de nota éa extinçâo local do peixe serra ou espadarte (Pristis perotteti Müller \& Henle, 1841), considerado um dos maiores peixes estuarinos, fato já observado em grande parte da sua distribuição geográfica, inclusive no litoral brasileiro (Simpfendorfer et al., 2008; Palmeira et al., 2012; FernandezCarvalho et al., 2013). Da mesma forma que observado por Marques (1991), os pescadores mais antigos de Fernão Velho afirmaram apenas ter "ouvido falar" no peixe serra, enquanto outros o descreveram com precisão.

Entre as espécies exóticas, a tilápia ( $O$. niloticus), o tucunarés (Cichla spp.) e o bagre africano (Clarias sp.) não foram reconhecidos pelos entrevistados como causadores de impactos ambientais, sendo considerados pelos pescadores como importantes substitutos de espécies nativas sobreexplotadas. Já a pirambeba (Serrasalmus branditi Lütken, 1875) foi citada como espécie exótica invasora com impacto negativo para a pesca, pois, além de danificar redes, predam ou mutilam os peixes emalhados nelas. Pompeu (1999) estudou a dieta da pirambeba, no rio São Francisco, registrando, predominantemente, peixes inteiros, escamas e pedaços de nadadeiras, corroborando as informaçóes dos pescadores. Além disso, é o único peixe citado como terapêutico na regiâo, cujo caldo, segundo o conhecimento ecológico local, tem propriedades afrodisíacas. Andrade \& Costa-Neto (2005) fizeram observaçóes semelhantes na cidade de Sáo Félix, Estado da Bahia.

Para os informantes, as principais causas da redução da produtividade pesqueira na lagoa Mundaú estão relacionadas à poluição das águas por esgotos domésticos e industriais, à deposição de lixo, à sobrepesca e a métodos predatórios de captura. Para Nogueira \& Sassi (2007), a redução dos recursos pesqueiros neste local é causada, principalmente, pela sobrepesca, consequência do aumento do número de desempregados que se tornam pescadores e não dominam as técnicas tradicionais de captura e manejo.

\section{CONCLUSÃO}

A regiáo estudada é proporcionalmente pequena em relaçáo à extensão do litoral alagoano, mas tem grande importância histórica, ambiental e cultural para o Estado. É, também, uma região sistematicamente impactada pela ação antrópica, especialmente a partir dos processos de urbanização e industrialização, que têm se intensificado nas últimas décadas. A pesca artesanal em Fernão Velho vem passando por contínua modificação, especialmente no contexto cultural, em que os mais jovens não são mais atraídos pela pesca, o que compromete a transição cultural dessa atividade. Como já apontado por Marques (1991) e Nogueira \& Sassi (2007), algumas das estratégias de pesca características da região devem desaparecer nos próximos anos devido ao declínio gradativo da atividade.

Apesar das adversidades, Fernáo Velho ainda abriga uma comunidade de pescadores tradicionais, que detém um conhecimento acurado sobre a construção e utilização dos apetrechos e atratores de pesca, além de informaçóes detalhadas sobre o estado da ictiofauna local. Portanto, para a conservação e valoração da identidade cultura da pesca na comunidade de Fernão Velho, faz-se necessário a implantação ou ampliação de estações de tratamento 
para reduzir os níveis de poluentes na bacia hidrográfica do rio Mundaú, a implementação de políticas voltadas à conservação dos estoques pesqueiros do CELMM, o manejo participativo aliado à pesquisa científica e o turismo de base comunitária. Essas são açóes prioritárias para reverter a progressiva marginalização da pesca artesanal na região estudada.

\section{AGRADECIMENTOS}

ÀcomunidadedeFernão Velho, em especial aospescadores, pela colaboração durante as entrevistas; a Carollinny Vilas Boas e Ruan C. P. Faquim (PPG em Diversidade Biológica e Conservação nos Trópicos - UFAL), pela colaboração nas atividades de campo, e à CAPES, pela bolsa concedida ao primeiro autor.

\section{REFERÊNCIAS BIBLIOGRÁFICAS}

Agência Nacional de Águas (2006) - Plano de Açôes e Gestão Integrada do Complexo Estuarino-Lagunar Mundaúl Manguaba (CELMM) - Resumo executivo. 124p., ENGECORPS - Brasília, DF, Brasil. ISBN: 85-8962909-0.

Alencar, C.A.G.; Maia, L.P. (2011) - Perfil socioeconômico dos pescadores brasileiros. Arquivos de Ciências do Mar, (ISSN: 0374-5686), 44(3):12-19, Fortaleza, CE, Brasil. Disponível em http://www.inct-tmcocean.com.br/pdfs/ Produtos/Artigos_periodicos/178_Perfil-economico-doCE.pdf

Alves, C.; Corrêa, F.; Bager, A.; Fernandes, J.P.L.; O; Piedras, S.R.N.P. (2009) - Ictiofauna capturada por pescadores artesanais na Lagoa Pequena - Regiāo estuarina da Lagoa dos Patos - RS. Biotemas (ISSN: 0103-1643), 22(3):229234, Florianópolis, SC, Brasil. Disponível em https:// www.academia.edu/440920/Ictiofauna_Capturada Por_Pescadores_Artesanais_Na_Lagoa_Pequena_ Regiao_Estuarina_Da_Lagoa_Dos_Patos_RS

Alves, R.R.N.; Nishida, A.K. (2003) - Aspectos socioeconômicos e percepçáo ambiental dos catadores de caranguejo-uçá Ucides cordatus cordatus (L. 1763) (Decapoda, Brachyura) do estuário do rio Mamanguape, Nordeste do Brasil. Revista Interciencia (ISSN:03781844), 28(1):36-43, Caracas, Venezuela. Disponível em http://www.redalyc.org/articulo.oa?id=33907606

Alves, R.R.N.; Souto, W.M.S. (2010) - Desafios e dificuldades associadas às pesquisas etnozoológicas no Brasil. In: Alves, R.R.N.; Souto, W.M.S.; Mourão, J.S. (Org.), A Etnozoologia no Brasil: importância, status atual e perspectivas, pp.57-65, NUPEEA, Recife, AL, Brasil. ISBN: 9788563756060.

Andrade, J.N.; Costa-Neto, E.M. (2005) - Primeiro registro da utilizaçáo medicinal de recursos pesqueiros na cidade de São Félix, Estado da Bahia, Brasil. Acta Scientiarum. Biological Sciences (ISSN:1807-863X), 27(2):177183, Maringá, PR, Brasil. Disponível em http://www. periodicos.uem.br/ojs/index.php/ActaSciBiolSci/article/ view/1328/766

Araguaia, C.D.O.; Pará, E.D.O. (2007) - Caracterização socioeconômica da pesca artesanal no município de Conceição do Araguaia, Estado do Pará. Amazônia -
Ciência \& Desenvolvimento (ISSN:1809-4058), 2(4):3751, Belém, PA, Brasil. Disponível em http://www.basa. com.br/bancoamazonia2/revista/edicao_04/revista_ amazonia_edicao_4_completa_final.pdf

Araújo, M.P.; Costa, T.L.F.; Carreira, R.S. (2011) - Esteróis como indicadores do acúmulo de esgotos domésticos em sedimentos de um sistema estuarino-lagunar tropical (Mundaú-Manguaba, AL). Revista Quimica Nova (ISSN:0100-4042), 34(1):64-70, São Paulo, SP, Brasil. Disponível em http://www.scielo.br/pdf/qn/v34n1/ v34n1a13.pdf

Barros, H.M.; Eskinazi-Leça, E.; Paranaguá, M.N. (2000) The disappearing fish: an understanding of sustainability among estuarine fishermen communities of Bragança, PA. Aquatic Ecosystem Health and Management, 3:553560. DOI: $10.1016 / S 1463-4988(00) 00040-3$

Biernacki, P.; Waldorf, D. (1981) - Snowball sampling problems and techniques of chain referral sampling. Sociological Methods \& Research November, 10:141-163. DOI: 10.1177/004912418101000205

Calheiros, D.F.; Seidl, A.F.; Ferreira, C.J.A. (2000) Participatory research methods in environmental science: local and scientific knowledge of a limnological phenomenon in the Pantanal wetland of Brazil. Journal of Applied Ecology (ISSN:1365-2664), 37:684-696. DOI: 10.1046/j.1365-2664.2000.00524.x

Cardoso, F.R. (2008) - Ecologia da pesca e biologia reprodutiva do acará-disco (Symphysodon aequifasciatus, Pellegrin 1904) (Perciformes: Cichlidae) na RDS Piagaçu-Purus, Amazônia Central: subsidios para o manejo sustentável de um recurso natural. 116p., Dissertação de Mestrado, Universidade Federal do Amazonas, Manaus, AM, Brasil. Disponível em http://tede.inpa.gov.br/tde_busca/ arquivo.php? codArquivo $=430$

Catella, A.C. (2007) - Aspectos ecológicos e culturais da pescaria de anzol. ADM - Artigo de Divulgação na Mídia, Embrapa Pantanal, 108:1-4, Corumbá, MS, Brasil. Disponível em http://www.infoteca.cnptia.embrapa.br/ bitstream/doc/812529/1/ADM108.pdf

Chaves, P.T.; Robert, M.C. (2003) - Embarcaçôes, artes e procedimentos da pesca artesanal no litoral sul do Estado do Paraná, Brasil. Atlântica, (ISSN: 2236-7586), 25:5359, Rio Grande, RS, Brasil. Disponível em http://www. lei.furg.br/atlantica/vol25/ob08.pdf

Cintra, I.H.A.; Juras, A.A.; Tenório, G.S.; Brabo, M.F.; Ogawa, M. (2009) - Embarcaçôes pesqueiras do reservatório da usina hidrelétrica de Tucuruí (Pará, Brasil). Boletim Técnico-Científico do Cepnor, 9(1):81-93. DOI: $10.4322 /$ rca.2011.039

Condini, M.V.; Garcia, A.M.; Vieira, J.P. (2007) - Descrição da pesca e perfil socioeconômico do pescador da garoupaverdadeira Epinephelus marginatus (Lowe) (Serranidae: Epinephelinae) no Molhe Oeste da Barra de Rio Grande, Rio Grande do Sul, Brasil. Pan-American Journal of Aquatic Sciences (ISSN:1809-9009), 2(3):279-287, Rio Claro, Brasil. Disponível em http://www.panamjas.org/ pdf_artigos/panamjas_2\%283\%29_279-287.pdf

Correia, M.D.; Sovierzoski, H.H. (2009) - Ecossistemas Costeiros de Alagoas - Brasil. 144p., Technical Books, Rio de Janeiro, RJ, Brasil. ISBN: 9788561368067 
Costa, F. (1980) - Documentário da ictiofauna da regiāo das lagoas Mundaú/Manguaba. 200p., SEPLAN/CDCT/ Governo do Estado de Alagoas, Alagoas, Brasil.

Costa-Neto, E.M. (2001) - A cultura pesqueira do litoral Norte da Bahia. 159p., Salvador, Maceió, AL, Brasil. EDUFBA/EDUFAL. ISBN 8523202463

Costa-Neto, E.M.; Marques, J.G.W. (2001) - Atividades de pesca desenvolvidas por pescadores da comunidade de Siribinha, município de Conde, Bahia: uma abordagem etnoecológica. Sitientibus Série Ciências Biológicas (ISSN: 1519-6097), 1(1):71-78, Feira de Santana, BA, Brasil. Disponível em http://www2.uefs.br/revistabiologia/SB_ v01.1_c09.zip

Di Ciommo, R.C. (2007) - Pescadoras e pescadores: a questão da equidade de gênero em uma reserva extrativista marinha. Ambiente \& Sociedade (ISSN:1414-753X), 10(1):151-163, São Paulo, SP, Brasil. Disponível em http://www.scielo.br/pdf/asoc/v10n1/v10n1a10.pdf

Diegues, A.C. (2001) - Ecologia humana e planejamento costeiro. 225p., NUPAUB/USP, São Paulo, Brasil. ISBN: 85-87304-03-8

Diegues, A.C. (2003) - Conhecimento e manejo tradicionais em áreas protegidas de uso sustentável: o caso da resex marinha do Arraial do Cabo-Rio de Janeiro. Disponível em http://nupaub.fflch.usp.br/sites/nupaub.fflch.usp.br/ files/color/resexarraial.pdf

Duarte, A.A.L.S.; Vieira, J.M.P. (1997) - Caracterização dos ambientes estuarinos: mistura em estuários. Engenharia Civil (ISSN: 0873-1152) 6:41-55, Guimarães, Portugal. Disponível em http://repositorium.sdum.uminho.pt/ bitstream/1822/2495/1/Num6_pag_41_55.pdf

Elliot, M.; Mclusky, D.S. (2002) - The need definitions in understanding estuaries. Estuarine, Coastal and Shelf Science, 55(6):815-827. DOI: 10.1006/ecss.2002.1031

Fadigas, A.B.M.; Garcia, L.G. (2012) - Conservation of the estuarine zone of the Goiana and Megaó rivers in northeastern Brazil: an analysis of the strategies adopted by fisherwomen communities. Revista da Gestão Costeira Integrada, 12(4):577-582. DOI: $10.5894 / \mathrm{rgci} 386$

Farias, I.S. (2012) - Dominação e resistência operária no núcleo fabril de Fernão Velho/AL (1953-1962). 115p., Dissertação de Mestrado - Universidade Federal de Alagoas, Maceió, AL, Brasil. Não Publicado.

Fernandez-Carvalho, J.; Imhoff, J.L.; Faria, V.V.; Carlson, J.K.; Burgess, G.H. (2013) - Status and the potential for extinction of the Largetooth Sawfish Pristis Pristis in the Atlantic Ocean. Aquatic Conservation: Marine And Freshwater Ecosystems (Published Online). DOI: 10.1002/ aqc. 2394

Ferreira, J.A. (2011) - A precarização da pesca artesanal e reprodução do espaço na região metropolitana do Rio de Janeiro (RMRJ). Revista Geográfica de América Central (ISSN: 2215-2563), 2(47):1-16, Costa Rica. Disponível em http://www.revistas.una.ac.cr/index.php/geografica/ article/view/2121

Gabor, M.R. (2007) - Types of non-probabilistic sampling used in marketing research. "Snowball Sampling". Journal Management \& Marketing (ISSN: 1472-1376) 2(3): sem paginação. Disponível em http://www. managementmarketing.ro/pdf/articole/72.pdf
Gianesella, S.M.F.; Saldanha-Corrêa, F.M.P. (2010) Sustentabilidade dos Oceanos. 199 p., Blucher, São Paulo, Brasil. ISBN: 9788521205777

IBAMA/SEAP/PROZEE (2008) - Monitoramento da atividade pesqueira no litoral nordestino - Projeto Estatpesca. 385p., Tamandaré, PE, Brasil. Disponível em www4. icmbio.gov.br/cepene/download.php?id_download=531

IMA (1992) - Decreto de Lei do Estado de Alagoas no 5.347 , de 27 de Maio de 1992. Maceió. IMA - Instituto do Meio Ambiente, Maceió, AL, Brasil. Disponível em http:// www.ima.al.gov.br/legislacao/leis-estaduais/Lei\%20 nb0\%205.347_92.pdf/view

Junior, W.M. (2010) - Adaptação dos Pescadores artesanais aos impactos ambientais sobre os manguezais do estuário da Baixada Santista. Fórum ambiental da Alta Paulista. (ISSN: 1980-0827), 6:698-711. Disponível em http:// www.amigosdanatureza.org.br/publicacoes/index.php/ forum_ambiental/article/download/31/33

Legendre, M. (1985) - Rapport de mission au Brésil et en Guyane du 20 août au 18 septembre. 31p., Centre de Recherches Océanographques, 18:1-25. Disponível em http://horizon.documentation.ird.fr/exl-doc/pleins_ textes/pleins_textes_6/b_fdi_35-36/40817.pdf

Lieber, M.D. (1994) - Traditional fishing on a Polynesian atoll. SPC Traditional Marine Resource Management and Knowledge Information Bulletin \#4 (ISSN: 10257497), 4:12-17. Disponível em http://www.spc.int/ digitallibrary/doc/fame/infobull/trad/4/trad4.pdf

Lima, B.B.; Velasco, G. (2012) - Estudo piloto sobre o autoconsumo de pescado entre pescadores artesanais do estuário da Lagoa dos Patos, RS, Brasil. Boletim do Instituto de Pesca (ISSN: 1678-2305), 38(4):357-367, São Paulo, SP, Brasil. Disponível em ftp://ftp.sp.gov.br/ ftppesca/38_4_357-367.pdf

Marques, J.G.W. (1991) - Aspectos ecológicos na etnoictiologia dos pescadores do Complexo Estuarino - Lagunar MundaúManguaba, Alagoas. 280p., Tese de Doutorado, Universidade de Campinas, Campinas. Não publicado

Martins, M.C. (2008) - Práticas de trabalho e produção de saberes no cotidiano de mulheres pescadoras. Sísifo Revista de Ciências da Educação (ISSN: 1646-4990), (6): 71-84, Lisboa, Portugal. Disponível em http://sisifo.fpce. ul.pt/pdfs/Sisifo6_D6_mariacristinamartins.pdf

Melo, T.S.; Lins, R.D.B. (2010) - O fenômeno dos assentamentos humanos precários em áreas urbanas ambientalmente frágeis: o caso das favelas do DiqueEstrada, em Maceió, Alagoas. $V$ Encontro Nacional da ANPPAS, Florianópolis, SC, Brasil. Disponível em http://www.anppas.org.br/encontro5/cd/artigos/GT3848-991-20100903191215.pdf

Melo-Magalhães, E.M.; Medeiros, P.R.P.; Lira, M.C.A.; Koening, M.L.; Moura, A.N. (2009) - Determination of eutrophic areas in Mundaú/Manguaba lagoons, Alagoas-Brazil, through studies of the phytoplanktonic community. Brazilian Journal of Biology (ISSN: 15196984), 69(2)271-280, São Carlos, SP, Brasil. Disponível em http://www.scielo.br/pdf/bjb/v69n2/06.pdf

Mendonça, J.T.; Katsuragawa, M. (2001) - Caracterização da pesca artesanal no complexo estuarino-lagunar de Cananéia-Iguape, Estado de São Paulo, Brasil (1995- 
1996). Acta Scientiarum-Biological Sciences (ISSN: $1807-$ 863X), 23(2):535-547, Maringá, PR, Brasil. Disponível em http://www.periodicos.uem.br/ojs/index.php/ ActaSciBiolSci/article/view/2713/2031

Montenegro, S.C.S.; Marques, J.G.W.; Nordi, N. (2007) - Os pescadores de camarão do Baixo São Francisco alagoano: abordagem etnoecológica com ênfase nas estratégias de pesca. In: Moura, F.B.P. (Org.), Conhecimento tradicional e estratégias de sobrevivência de populaçóes brasileiras, pp.105-122, EDUFAL, Maceió, AL, Brasil. ISBN: 97885-7177-351-6.

Mourão, J.S.; Nordi, N. (2003) - Etnoictiologia de pescadores artesanais do estuário do rio Mamanguape, Paraíba, Brasil. Boletim do Instituto da Pesca (ISSN: 16782305), 29(1)9-17, São Paulo, Brasil. Disponível em ftp:// ftp.sp.gov.br/ftppesca/mourao.pdf

Nascimento, M.S.V.; Sassi, R. (2007) - Análise da atividade pesqueira e das condiçóes socioeconômicas dos pescadores artesanais de Cajueiro da Praia, Estado do Piauí, Brasil. Gaia Scientia (ISSN: 1981-1268), 1(2):141-154, João Pessoa, PB, Brasil. Disponível em http://periodicos.ufpb. br/ojs/index.php/gaia/article/view/2270/1996

Nishida, A.K.; Nordi, N.; Alves, R.R.N. (2008a) - Aspectos socioeconômicos dos catadores de moluscos do litoral paraibano, Nordeste do Brasil. Revista de Biologia e Ciências da Terra (ISSN: 1519-5228), 8(1):207-215. Disponível em http://eduep.uepb.edu.br/rbct/sumarios/ pdf/22Nishida.pdf

Nishida, A.K.; Nordi, N.; Alves, R.R.N. (2008b) Embarcaçóes utilizadas por pescadores estuarinos da Paraíba, Nordeste do Brasil. Biofar: Revista de Biologia e Farmácia (ISSN: 1983-4209), 3(1)1-8. Disponível em http://sites.uepb.edu.br/biofar/download/v3n12008/EMBARCAOCOES_UTILIZADAS_POR_ PESCADORES.pdf

Nogueira, E.M.S. (2005) - Estudo da produtividade das caiçaras do Complexo Estuarino-Lagunar Mundaú-Manguaba (Alagoas) e condiçóes socioeconômicas dos pescadores. $155 \mathrm{p}$., Tese de Doutorado, Universidade Federal da Paraíba, João Pessoa PB, Brasil. Não Publicado.

Nogueira, E.M.S.; Sassi, R. (2007) - A arte das caiçaras e o conhecimento dos caiçareiros de Alagoas. In: Moura, F. B. P. (Org.)., Conhecimento tradicional e estratégias de sobrevivência de populaçóes brasileiras, pp.91-103, EDUFAL, Alagoas. ISBN: 978-85-7177-351-6.

Osório, F.M.; Godinho, W.O.; Lotufo, T.M.C. (2011) - Ictiofauna associada às raízes de mangue do Estuário do Rio Pacoti CE, Brasil. Biota Neotropica (ISSN: 16760603), 11(1):1-6. Disponível em http://www.scielo.br/ pdf/bn/v11n1/38.pdf

Palmeira, A.R.O.; Rosa, R.S.; Sampaio, C.L.S. (2012) Capturas de Pristis perotteti Müller \& Henle, 1841 no litoral paraense, uma possível espécie bandeira para os estuários da região Norte do Brasil. In: Encuentro Colombiano Sobre Condrictios, III, Resumos Expandidos. Santa Marta: Fundación Squalus.

Paz, V.A.; Begossi, A. (1996) - Ethnoichthyology of gamboa fishermen of Sepetiba Bay, Brazil. Journal of Ethnobiology (ISSN: 0278-0771), 16(2):157-168. Disponível em http://ethnobiology.org/sites/default/files/pdfs/ JoE/16-2/PazandBegossi1996.pdf
Pedrosa, B.M.J.; Lira, L.; Maia, A.L.S. (2013) - Pescadores urbanos da zona costeira do Estado de Pernambuco, Brasil. Boletim do Instituto de Pesca (ISSN: 1678-2305), 39(2):93106. ftp://ftp.sp.gov.br/ftppesca/39_2_93-106.pdf

Pena, P.L; Freitas, M.C.S.; Cardim, A. (2011) - Trabalho artesanal, cadências infernais e lesóes por esforços repetitivos: estudo de caso em uma comunidade de mariscadeiras na Ilha de Maré, Bahia. Ciências of saúde coletiva (ISSN: 1413-8123), 16(8):3383-3392. Disponível em http://www.scielo.br/pdf/csc/v16n8/ a05v16n8.pdf

Pereira-Barros, A.T.L.; Pereira-Barros, J.B. (1987) Importância socioeconômica do sururu (Mytella falcata - Mollusca - Mytilidae) para a população da cidade de Coqueiro Seco. Boletim de Estudo de Ciências do Mar (ISSN: 0102-8596), 6:49-64.

Pereira-Barros, A.T.L.; Pereira-Barros, J.B. (1988) - Estudo comparativo da importância do sururu (Mytella falcataMollusca - Mytilidae) entre as populaçóes de Fernão Velho e Rio Novo. Boletim de Estudo de Ciências do Mar (ISSN: 0102-8596), 7:21-24.

Pieve, S.M.N.; Kubo, R.R.; Souza, G.C. (2009) - Pescadores artesanais da Lagoa Mirim: etnoecologia e resiliência. 243p., MDA, Brasília, Brasil. ISBN: 978-85-60548-55-2.

PLEC (1980) - Projeto de Levantamento ecológico e cultural da região das lagoas Mundaú e Manguaba. Maceió: Secretaria do Estado do Governo de Alagoas. Vol. II, p. 335-605.

Pompeu, P. S. (1999) - Dieta da pirambeba Serrasalmus brandtii Reinhardt (Teleostei, Characidae) em quatro lagoas marginais do rio São Francisco, Brasil. Revista Brasileira de Zoologia (ISSN: 0101-8175), 16(2):1926. Disponível em http://dx.doi.org/10.1590/S010181751999000600003

Porcher, L.C.F.; Poester, G.; Lopes, M.; Schonhofen, P.; Silvano, R.A.M. (2010) - Percepção dos moradores sobre os impactos ambientais e as mudanças na pesca em uma lagoa costeira do litoral sul do Brasil. Boletim do Instituto de Pesca (ISSN: 1678-2305), 36(1):61-72. Disponível em ftp://ftp.sp.gov.br/ftppesca/36_1_61-72.pdf

Ramires, M.; Barrella, W.; Esteves, A.M. (2012) Caracterização da pesca artesanal e o conhecimento pesqueiro local no Vale do Ribeira e litoral sul de São Paulo. Revista Ceciliana (ISSN: 2175-7224), 4(1): 37-43. Disponível em http://sites.unisanta.br/revistaceciliana/ edicao_07/1-2012-37-43.pdf

Reis, E.G.; D'incao, F. (2000) - The present status of artisanal fisheries of extreme Southern Brazil: an effort towards community-based management. Ocean \& Coastal Management, 43(7):585-595. doi:10.1016/ S0964-5691(00)00048-X

Rios, A.O.; Rego, R.C.F.; Pena, P.G.L. (2011) - Doenças em trabalhadores da pesca. Revista Baiana de Saúde Pública (ISSN: 01000233), 35(1):175-188. http://inseer.ibict. br/rbsp/index.php/rbsp/article/viewFile/19/12

Rosa, I.L.; Oliveira, T.P.R.; Osório, F.M.; Moraes, L.E.; Castro, A.L.C.; Barros, G.M.L.; Alves, R.R.M. (2011) - Fisheries and trade of seahorses in Brazil: historical perspective, current trends, and future diretions. Biosiversity Conservation, 20(9):1951-1971. doi: 10.1007/ s10531-011-0068-2 
Sampaio, C.L.S.; Nottingham, M.C. (2007) - Guia para Identificação de Peixes Ornamentais: Espécies Marinhas. Vol I. 205p., IBAMA, Brasília, Brasil. ISBN: 978-857300-250-8

Sant'Ana, M.M. (1970) - Contribuição à história do açúcar em Alagoas. 514p., Museu do Açúcar, Pernambuco, Brasil. ISBN: 978-85-62030-18-5.

Sarmento, I. (2002) - Recuperação dos espaços públicos e edifícios históricos do núcleo central de Fernão Velho. 97p., Monografia de Conclusão de Graduação, Universidade Federal de Alagoas, Maceió, AL, Brasil. Não publicado.

Silva, C.S.; Pereira-Barros, J.B. (1987) - Inventário da malacofauna do Complexo Lagunar Mundaú-Manguaba, Alagoas. Boletim de Estudo da Ciência do Mar (ISSN 0102-8596), (6): 65-74.

Wright, R.;Stein,M.(2005)-Snowball sampling. Encyclopedia of social Measurement, 3-495-500. Disponível em http:// dx.doi.org/10.1016/B0-12-369398-5/00087-6

Walter,T.; Wilkinson, J.; Silva, P.A. (2012) - A análise da cadeia produtiva dos catados como subsídio à gestão costeira: as ameaças ao trabalho das mulheres nos manguezais e estuários no Brasil. Revista da Gestão Costeira Integrada, 12(4):483-497. doi: 10.5894/rgci346

Vieira, N.C.; Moraes, S.C.; Nunes, Z.M.P. (2013) - A study of fishing and educational level of young fishers on the Bonifácio Village, Bragança, Pará, Northern Coast of Brazil. Boletim do Instituto de Pesca (ISSN 1678-2305), 39(2):195-204. Disponível em ftp://ftp.sp.gov.br/ Ftppesca/39_2_195-204.Pdf

Troca, D.F.A.; Vieira, J.P. (2012) - Potencial invasor dos peixes não nativos cultivados na região costeira do Rio Grande do Sul, Brasil. Boletim do Instituto de Pesca (ISSN 1678-2305), 38(2):109-120. Disponível em ftp://ftp. sp.gov.br/ftppesca/38_2_109-120.pdf

Teixeira, R.L.; Sá, H.S. (1998) - Abundância de macrocrustáceos decápodas nas áreas rasas do Complexo Lagunar Mundaú/Manguaba, AL. Revista Brasileira de Biologia (ISSN: 0034-7108), 58(3):393-404. Disponível em http://www.scielo.br/pdf/rbbio/v58n3/4567.pdf

Teixeira, R.L.; Falcão, G.A.F. (1992) - Composição da fauna nectônica do Complexo Lagunar Mundaú/Manguaba, Maceió, AL. Atlântica (ISSN: 0102-1656), 4:43-58.

Suhogusoff, V.G.; Piliackas, J.M. (2007) - Breve histórico da ação antrópica sobre os ecossistemas costeiros do Brasil com ênfase nos manguezais do estado de Sáo Paulo. Revista Integração (ISSN: 1413-6147), 51:343-352. Disponível em ftp://ftp.usjt.br/pub/revint/343_51.pdf
Souza, M.R.; Barrella, W. (2001) - Conhecimento popular sobre peixes numa comunidade caiçara da estação ecológica de Juréia-Itatins/ SP. Boletim do Instituto de Pesca (ISSN: 1678-2305), 27(2):123-130. Disponível em ftp://ftp.sp.gov.br/ftppesca/27\%5B2\%5D-art-01.pdf

Souza, M.R.M.; Neumann-Leitão, S. (2000) - Consequências socioeconômicas dos impactos antrópicos no estuário do rio São Francisco em Brejo Grande, Sergipe - Brasil. Trabalhos Oceanográficos da Universidade Federal de Pernambuco (ISSN: 1679-3013), 28(1):97-116. Disponível em http://www.ufpe.br/tropicaloceanography/artigos_ completos_resumos_t_d/28_2000_2_souza.pdf

Simpfendorfer, C.A.; Poulakis, G.R.; O’Donnell, P.M.; Wiley, T.R. (2008) - Growth rates of juvenile smalltooth sawfish Pristis pectinata Latham in the Western Atlantic. Journal of Fish Biology, 72(3):711-723. doi:10.1111/ j.1095-8649.2007.01764.x

Silvano, R.A.M.; Udvardy, S.; Ceroni, M.; Farley, J. (2005) - An ecological integrity assessment of a Brazilian Atlantic Forest watershed based on surveys of stream health and local farmers' perceptions: implications for management. Ecological Economics (ISSN: 09218009), 53:369-385. DOI: http://dx.doi.org/10.1016/j. ecolecon.2004.12.003

Silvano, R.A.M.; Silva, A.L.; Ceroni, M.; Begossi, A. (2008) - Contributions of ethnobiology to the conservation of tropical rivers and streams. Aquatic Conservation: Marine and Freshwater Ecosystems (ISSN: 1099-0755), 18:241-260. DOI http://dx.doi.org/10.1002/aqc.825

Silva, M.C.; Oliveira, A.S.; Nunes, G.Q. (2007) Caracterizaçáo socioeconômica da pesca artesanal no município de Conceição do Araguaia, Estado do Pará. Amazônia: Ciência \& Desenvolvimento (ISSN 18094058) 2(4):37-51. Disponível em http://www.basa.com. br/bancoamazonia2/Revista/edicao_04/CD_Vol_IV_ Caracterizacao-socio.pdf

Silva, D.F.; Souza, F.A.S. (2009) - Proposta de manejo sustentável para o Complexo Estuarino-Lagunar Mundaú/Manguaba (AL). Revista Brasileira de Geografia Física (ISSN 1984-2295), 1(2):78-94. Disponível em http://www.revista.ufpe.br/rbgfe/index.php/revista/ article/viewFile/30/32 